\title{
BMJ Open The Young Disability Questionnaire- Spine: item development, pilot testing and conceptualisation of a questionnaire to measure consequences of spinal pain in children
}

\author{
Emilie Meldgaard, ${ }^{1}$ Henrik Hein Lauridsen (D) , ${ }^{1}$ Lise Hestbaek (D) ${ }^{1,2}$
}

To cite: Meldgaard $\mathrm{E}$, Lauridsen HH, Hestbaek L. The Young Disability QuestionnaireSpine: item development, pilot testing and conceptualisation of a questionnaire to measure consequences of spinal pain in children. BMJ Open 2021;11:e045580. doi:10.1136/ bmjopen-2020-045580

- Prepublication history and additional supplemental materials for this paper are available online. To view these files, please visit the journal online (http://dx.doi.org/10. 1136/bmjopen-2020-045580).

Received 12 0ctober 2020 Revised 06 January 2021 Accepted 23 March 2021

Check for updates

(c) Author(s) (or their employer(s)) 2021. Re-use permitted under CC BY-NC. No commercial re-use. See rights and permissions. Published by BMJ.

${ }^{1}$ Department of Sports Science and Clinical Biomechanics, University of Southern Denmark, Odense, Denmark

${ }^{2}$ Chiropractic Knowledge Hub, University of Southern Denmark, Odense, Denmark

Correspondence to

Dr Lise Hestbaek;

I.hestbaek@nikkb.dk

\section{ABSTRACT}

Objective The objective of the present study was to develop a questionnaire to measure the consequences of neck, midback and low back pain, relevant for schoolchildren aged 9-12 years.

Design The development of the questionnaire was carried out in three phases: (1) generation of items, (2) pilot testing and (3) conceptualisation.

Setting Danish primary schools.

Participants Children aged $9-12$ years from a local school were invited for completion of questionnaires and subsequent interviews.

Methods In phase 1 an extensive literature search identified items from existing questionnaires measuring musculoskeletal disability in children. These were added to items from a previously conducted qualitative study and constituted the basis for the new questionnaire. In phase 2 two consecutive pilot tests were performed to test for comprehension and feasibility of the questionnaire. Phase 3 consisted of a categorisation of the newly developed items according to the WHO's International Classification of Functioning, Disability and Health (ICF).

Results The combination of the previously conducted qualitative study and the literature review resulted in an item pool of 35 items. Through the process of item formulation and pilot testing, these were reduced to 28 items in the final questionnaire, which represented all categories in the ICF model. The qualitative study identified codes giving relative weight to four important domains. These were not included in any of the existing questionnaires but were added to the new questionnaire. Conclusions We developed the first version of a questionnaire to measure the consequences of back or neck pain in children. The process showed the importance of combining research methods, each adding important contributions to the final product. Subsequent work will finalise the questionnaire, allowing various options for use of the questionnaire.

\section{INTRODUCTION}

In Denmark, it is estimated that $30 \%$ of all schoolchildren have experienced spinal pain during the last year, ${ }^{1}$ and up to $20 \%$ have both frequent and intense pain. ${ }^{2}$ Furthermore,
Strengths and limitations of this study

- Combining qualitative interview findings with a systematic search of the literature proved to be beneficial to cover all potential aspects of consequences, as neither method was comprehensive by itself.

- The pilot testing of the resulting questionnaire also turned out to be necessary to improve the wording.

- We believe the stepwise process has helped to produce a questionnaire which is both comprehensive, covering all relevant aspects of spinal pain consequences, and understandable to the age group.

- The applicability of the questionnaire in other contexts and cultures is unknown.

spinal pain often tracks from adolescence into adulthood, ${ }^{3}$ where it becomes a major burden for both the individual and the society. ${ }^{4}$ However, the impact of spinal pain in children is only sparsely reported in the literature. ${ }^{5}$ This is partly because most spinal research has focused on adult populations, but also because research in children is hampered by a lack of validated instruments to measure the consequences of spinal pain. Several questionnaires measuring physical function and impact on everyday life in children have been published, but most of them are targeted specific patient or population groups, for example, children with juvenile idiopathic arthritis or athletes. ${ }^{78}$ Attempts have also been made to adapt functional limitations questionnaires developed for adults to use in children, but validation of these paediatric versions has not been carried out. ${ }^{9}$ Recent research suggests that the content of commonly used adult questionnaires is not suitable for children due to differences at the cognitive, physical and social level. ${ }^{5} 1011$ Consequently, there is a need to develop a sound and well-validated 
questionnaire measuring the consequences of spinal pain in children and adolescents.

In 2016, following the development of a questionnaire to measure the frequency and intensity of spinal pain in children (Young Spine Questionnaire, YSQ), our research team launched a programme to also develop a questionnaire to measure the consequences of spinal pain in children aged 9-12 years (Young Disability Questionnaire). The first step in this process was a qualitative investigation to identify which consequences of spinal pain are important to children. ${ }^{12}$ Based on the results from that study and on the previous literature, the aim of the present study is to develop a questionnaire (Young Disability QuestionnaireSpine, YDQ-S) to measure relevant consequences of neck, midback and low back pain in schoolchildren aged 9-12 years. The questionnaire will subsequently undergo a field test.

\section{METHODS}

The development of the YDQ-S was carried out in three phases: (1) item generation, (2) pilot testing and (3) conceptualisation.

\section{Item generation}

The primary purpose of the item generation phase was to generate an exhaustive pool of relevant items before the pilot test. ${ }^{13}$ The item generation was performed in four steps, where step 1 was a systematic literature search, carried out to identify existing questionnaires used to measure musculoskeletal (MSK) function/disability in children or adolescents. In step 2, experts in the field were consulted to ensure that all relevant questionnaires were retrieved and included. Step 3 was to compare codes developed in the previous qualitative study of Danish schoolchildren aged 9-12 years old with spinal pain, ${ }^{12}$ with the content of the questionnaires identified in steps 1 and 2. Finally, in step 4, all the resulting codes and questionnaire contents were formulated into questionnaire items.

\section{Systematic literature search}

The search strategy was developed by EM with the assistance of a research librarian. The Ovid databases Medline and Embase were used in the systematic literature search to locate publications that included measurement of function and pain-related disability in children and adolescents using an identifiable questionnaire. The core search terms consisted of four main concepts: instrument, function, target population and pain. Both keywords, medical subject headings $(\mathrm{MeSH})$ terms and Emtrees were used. To avoid a large number of articles concerning disabled children, an additional search was carried out in each database. This search consisted of the same core search terms but with the addition of a disabled concept; the two searches in each database were labelled 'full search' and 'disabled children', respectively (online supplemental material 1). The search results were separately imported to EndNote V.X8, where a duplicate search across the two databases was conducted and articles relating to disabled children were discarded (figure 1). The remaining articles from the two database searches were then combined and duplicate articles deleted. Screening of titles and abstracts was followed by reading full-length articles with focus on the inclusion and exclusion criteria, as shown in table 1 .

The original versions of the questionnaires used in the included articles were obtained and subjected to a face validity check. The face validity check consisted of a subjective assessment of relevance in relation to the purpose of the present study (consequences of spinal pain). Articles using questionnaires that could not be accessed in full original version were excluded.

An additional search was performed to investigate the existence of adult questionnaires validated on children (online supplemental material 2). This search was conducted in Medline and Embase with both keywords, $\mathrm{MeSH}$ terms and Emtrees searches. Questionnaires validated on children were included if the same inclusion and exclusion criteria as described in table 1 were fulfilled.

\section{Experts in the field}

To supplement the systematic literature search, two external experts known to be working within the same field of research were contacted and they contributed with a list of questionnaires, identified in a previously conducted systematic search of the literature which aimed to describe the psychometric properties of common selfreported multidimensional pain questionnaires for children and adolescents (S. Chan and A. Wong, The Hong Kong Polytechnic University, personal communication, unpublished). All the questionnaires obtained from their literature search were also screened for face validity.

\section{Comparison of codes}

To create an item pool, codes from the previously conducted qualitative study ${ }^{12}$ were entered into a table as reference codes. ${ }^{13}$ Items from the included questionnaires concerning the consequences of MSK pain were then linked to the reference codes. Items that did not fit the content of the reference codes were included as new items. All items were ordered thematically.

\section{Item formulation}

Because the chosen age group can reflect on themselves and provide valuable health information, a self-report questionnaire was chosen instead of a parent by proxy measure. ${ }^{14}$

The development of new item formulations was conducted by LH and EM, and the formulation of these was based on the comparison of reference codes and questionnaire items. The items were phrased corresponding to the overall thematic meaning of the compared items and carefully worded for the target age group. The new items were uniformly worded to allow for consistent language in the questionnaire. All were constructed with 


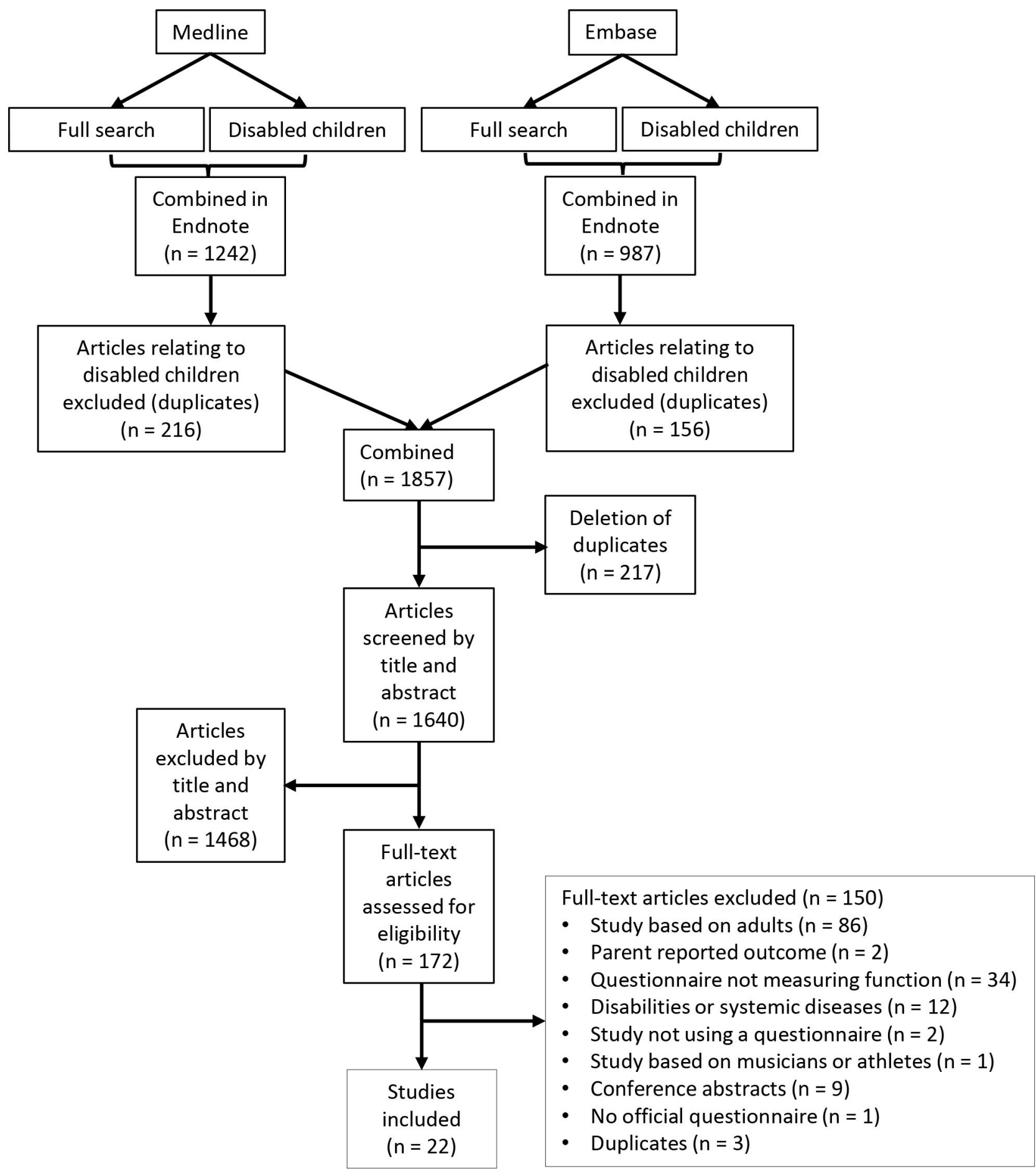

Figure 1 Flow chart of literature search to identify existing questionnaires used to measure musculoskeletal function/disability in children or adolescents.

the 'usual' state as a reference and starting with 'When I have pain...' to prevent any misunderstandings and to enhance feasibility. ${ }^{13}$

The response options were categorised into five levels of frequency: 'never', 'once or twice', 'often', 'very often' and 'almost all the time'.

In addition, the qualitative study identified codes giving relative weight to themes or domains, that is, 'The worst is .....'. Such a relative weight was not included in any of the existing questionnaires and could not be worded within the same framework. Therefore, this was not included in the comparison with existing questionnaires but was used to create an additional section for the questionnaire, which was placed at the end of the questionnaire. The four items in the additional section were to be rated from 1 to 10 , with 1 representing 'not important at all' and 10 representing 'the absolute most important'. The purpose of this section was to give children the possibility 
Table 1 Inclusion and exclusion criteria for the selection of articles

\begin{tabular}{ll}
\hline Inclusion criteria & Exclusion criteria \\
\hline Articles relating to & Articles relating to adults. \\
musculoskeletal pain in & Articles relating to athletes, \\
children or adolescents. & musicians or other specific \\
Some measure of & groups. \\
disability, function or & Articles based on disabled \\
quality of life must be & children or children with \\
included. & systemic diseases. \\
Articles using or referring & Outcomes not measuring \\
to an identifiable & function or physical \\
questionnaire. & limitations. \\
Articles must be written & \\
in English, German, & \\
Swedish, Norwegian or & \\
Danish. & \\
\hline
\end{tabular}

to report the relative importance of the four domains: pain intensity, movement restrictions, social impairment, and impact on mood and concentration.

\section{Pilot testing}

Two pilot tests were carried out to test for feasibility, understanding and ambiguity of both items and response options, and allowed the pupils the opportunity to elaborate on their answers and express if they felt anything was missing. The questions were modified based on the answers from pilot test 1 and were tested again in pilot test 2.

\section{Pilot test 1}

Pilot test 1 included three classes from third, fifth and sixth grades, respectively, at a private school located in Odense, Denmark. Information letters and informed consent forms were sent to the parents prior to the test, and information letters were handed out to the pupils who were present on the day. Two days later, the children completed the questionnaires and were interviewed during school hours. The three classes included 66 pupils in total, but only pupils who returned a signed consent form participated in the study. The pupils filled out a questionnaire booklet consisting of sections 1-3 of the YSQ ${ }^{15}$ followed by the newly developed consequencerelated items as well as the additional section with the four 'The worst is ......' questions. Pupils with pain at least once or twice in either the neck or back according to the YSQ were interviewed with their completed questionnaire as the starting point, allowing them to elaborate on their answers and add new information. All three authors participated in the interviews.

\section{Pilot test 2}

Pilot test 2 was conducted by EM at the same school 5 days following pilot test 1 using the same procedures. A group of fourth-grade and fifth-grade pupils, who did not participate in pilot test 1 , participated in the test. The questionnaire items were refined after pilot test 2 , and this will comprise the field test version of the YDQ-S.

\section{Pilot test 3}

A third pilot test could be conducted if all issues were not clear after the second pilot test. However, this did not prove necessary.

\section{Pilot test data analysis}

Following each pilot test, the three authors together compared the completed questionnaires with the notes from the interviews, and for each child discussed the discrepancies as well as potential misunderstandings.

\section{Conceptualisation}

The WHO International Classification of Functioning, Disability and Health (ICF) conceptualisation model ${ }^{16}$ is a classification tool used to describe functional states associated with health conditions covering two parts: one covering functioning and disability, and the other covering contextual factors. ${ }^{17}$ This provides a framework for describing health and health-related circumstances. ${ }^{18}$ We chose the ICF model because it provides a framework for measuring health according to the biopsychosocial model. ${ }^{19}$ Second, the ICF model is specific for describing health-related functioning and disability and can be used to explain both the health of individuals and the health of groups. ${ }^{20}$

The conceptual framework of this questionnaire follows a reflective model given that the items are reflections of the consequences of back and neck pain. If there is any change in experienced pain, then there should be a change in the responses to all items. ${ }^{13}$

\section{Patient and public involvement}

Patients or the public were not involved in the design, or conduct, or reporting or dissemination plans of our research.

\section{RESULTS}

\section{Item generation}

Systematic literature search

The Medline searches resulted in a total of 1242 articles, of which 216 were excluded because they included disabled children. The Embase searches resulted in a total of 987 articles, of which 156 articles were excluded because they included disabled children (figure 1).

After combining the Medline and the Embase searches, 1640 articles were left for screening. Titles and relevant abstracts were screened by EM for eligibility using the inclusion/exclusion criteria, resulting in the exclusion of 1468 articles. The remaining 172 references were browsed as full-text articles and reduced to 22 included articles. All included articles were examined for the use of questionnaires, and a total of eight different questionnaires were identified. These were screened and five questionnaires fitted the inclusion criteria and assessment of face validity 
and were included in the study: Functional Disability Inventory (FDI), ${ }^{21}$ PROMIS Pediatric Profile-49 (PROMIS),${ }^{22}$ Pediatric Quality of Life Inventory (PedsQL) ${ }^{23}$ KIDSCREEN-52 ${ }^{24}$ and YSQ. ${ }^{15}$ Three questionnaires were excluded due to poor face validity (Child Activity Limitations Interview-21 25 ) or were not developed for children (Short Questionnaire to Assess Health-Enhancing Physical Activity ${ }^{26}$ and Hannover Functional Ability Questionnaire ${ }^{27}$ ).

No relevant questionnaires were identified during the additional search for adult questionnaires validated on children.

\section{Experts in the field}

The external experts provided one new questionnaire that had not already been identified in the literature search: the Bath Adolescent Pain Questionnaire (BAPQ). ${ }^{28}$ This questionnaire fulfilled the inclusion and exclusion criteria. The face validity was considered adequate and the questionnaire was included.

Thus, the two-step search for relevant questionnaires resulted in a total of six different questionnaires to form the basis of the item pool: FDI, PROMIS, Peds-QL, KIDSCREEN-52, BAPQ and YSQ.

\section{Comparison of codes}

A face validity check of the 17 reference items developed from the qualitative study resulted in the removal of 2 items which do not describe a consequence ('cause of pain unknown' and 'pain intensity') and 4 items were removed due to overlapping meaning: 'improving factors' and 'strategies to improve the pain' were combined into 'strategies to improve the pain'; 'difficulties to define the pain' was considered covered by 'worrying about spinal pain'; 'reduction in participation' was considered covered by 'physical limitations'; and 'do not want to talk to others about the pain' was considered covered by 'talking with friends' and 'talking with parents'.

The resulting 11 reference codes were listed and linked with all items from the existing questionnaires. The results are shown in table 2.

Three reference codes ('physical limitations', 'social limitations' and 'worrying about spinal pain') were split up into five, four and three items, respectively, to cover all items from the questionnaires. For example, "physical limitations' was split into five items covering several specific activities: walking, running, taking care of myself, doing sports and playing, corresponding to the items found in the questionnaires forming the item pool. One reference code ('worsening factors') was not related to any questionnaire items and was removed from the item pool, since it is reflected in the questions describing limitations. Eight items from the questionnaires were not linked to any reference code.

\section{Item formulation}

The new items based on the item pool, including both the reference codes and the questionnaire items, are listed in table 2 . These 25 items were converted into questionnaire format and tested in the first pilot test.

\section{Pilot testing}

\section{Pilot test 1}

Three classes (third, fifth and sixth) completed the questionnaire; 34 of the pupils had returned a signed consent and 4 of these did not recall ever having experienced neck or back pain, leaving 30 pupils with present or past spinal pain for interviews. Questionnaire completion lasted for 12 and $25 \mathrm{~min}$, depending on the individual child's reading proficiency and contextual understanding as well as the level of concentration.

The questionnaire was revised based on interview notes and subsequent discussion among the three interviewers (EM, HHL and LH), and the changes along with the justifications for these are presented in table 3 . The response options caused confusion among the children and were therefore changed. Also, the children had difficulties understanding the concept in the additional section of the questionnaire, containing 'The worst is....' items and therefore this was revised. The introductory text to the final four items was rephrased from 'The worst thing about having spinal pain is...' to 'What matters most to you when having spinal pain?'

Four new items were added: 'pain when bending my neck', 'bending forward', 'riding my bicycle' and 'become quiet'; the item concerning participation in school was removed due to an overlap with the item regarding concentration. Three questions were rephrased to increase understanding, and finally the order of the items was reconsidered (table 3).

\section{Pilot test 2}

Seven pupils participated in pilot test 2 and tested the implemented changes. The time of completion was unchanged compared with the first pilot test. Interviews focused on the comprehension of the new response options and items, as well as additional comments from the pupils. Furthermore, the words 'quiet' and 'energy' were checked for comprehension because the interviewers were uncertain about these words during the first pilot test.

All seven pupils understood the meaning of the two words, the new response options did not cause any problems, and the change in the additional section ('What matters most .......') made the task easier to understand. However, the item 'When I have pain, I get grumpy or angry more easily' was changed to 'When I have pain, I get grumpy or annoyed more easily' because many of the pupils used the word 'annoyed' instead of 'angry' (also noted several times during the first pilot test).

Thus, a third round was not considered necessary.

\section{Conceptualisation}

All the components of the ICF were represented within the newly developed items (figure 2). Nine items 


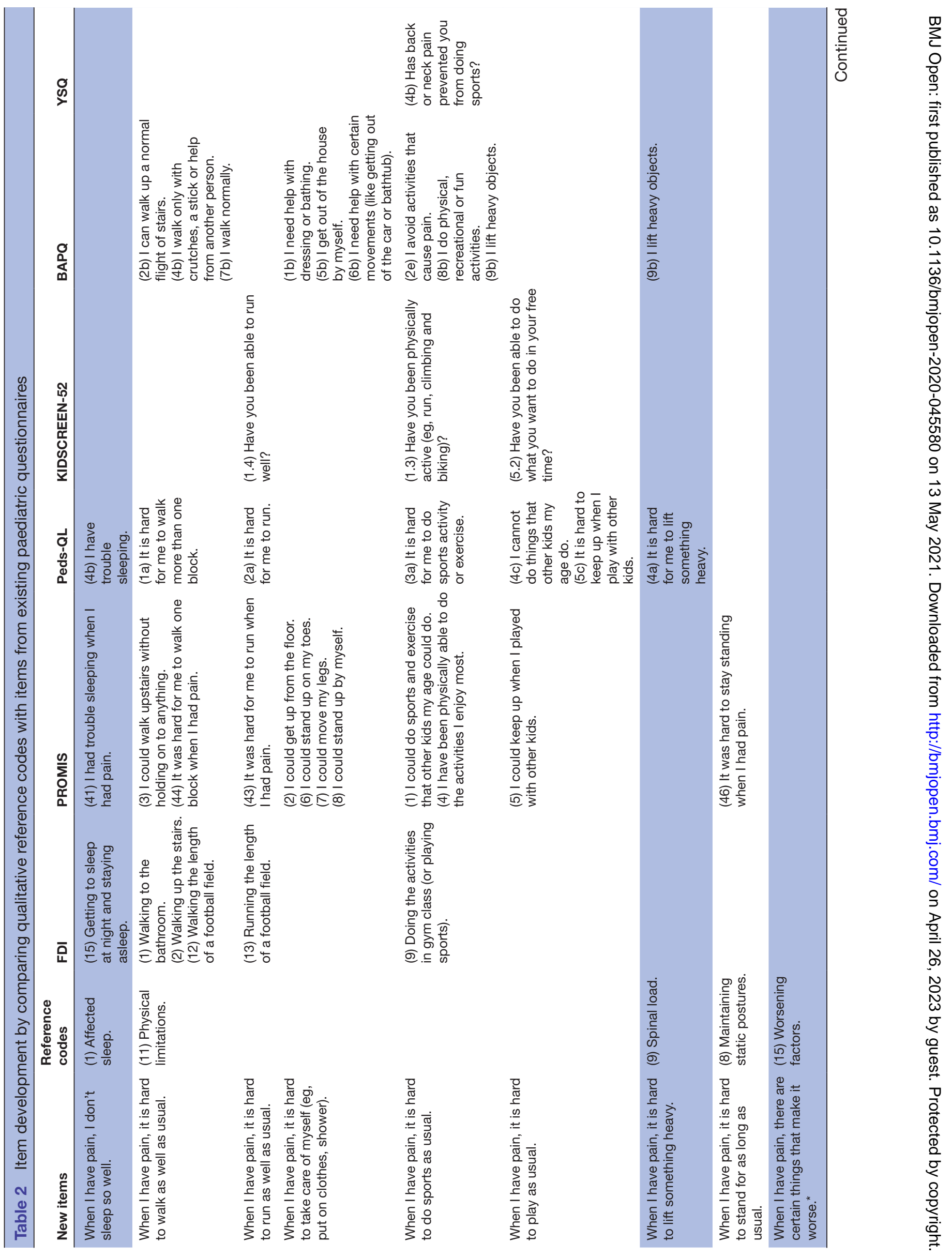




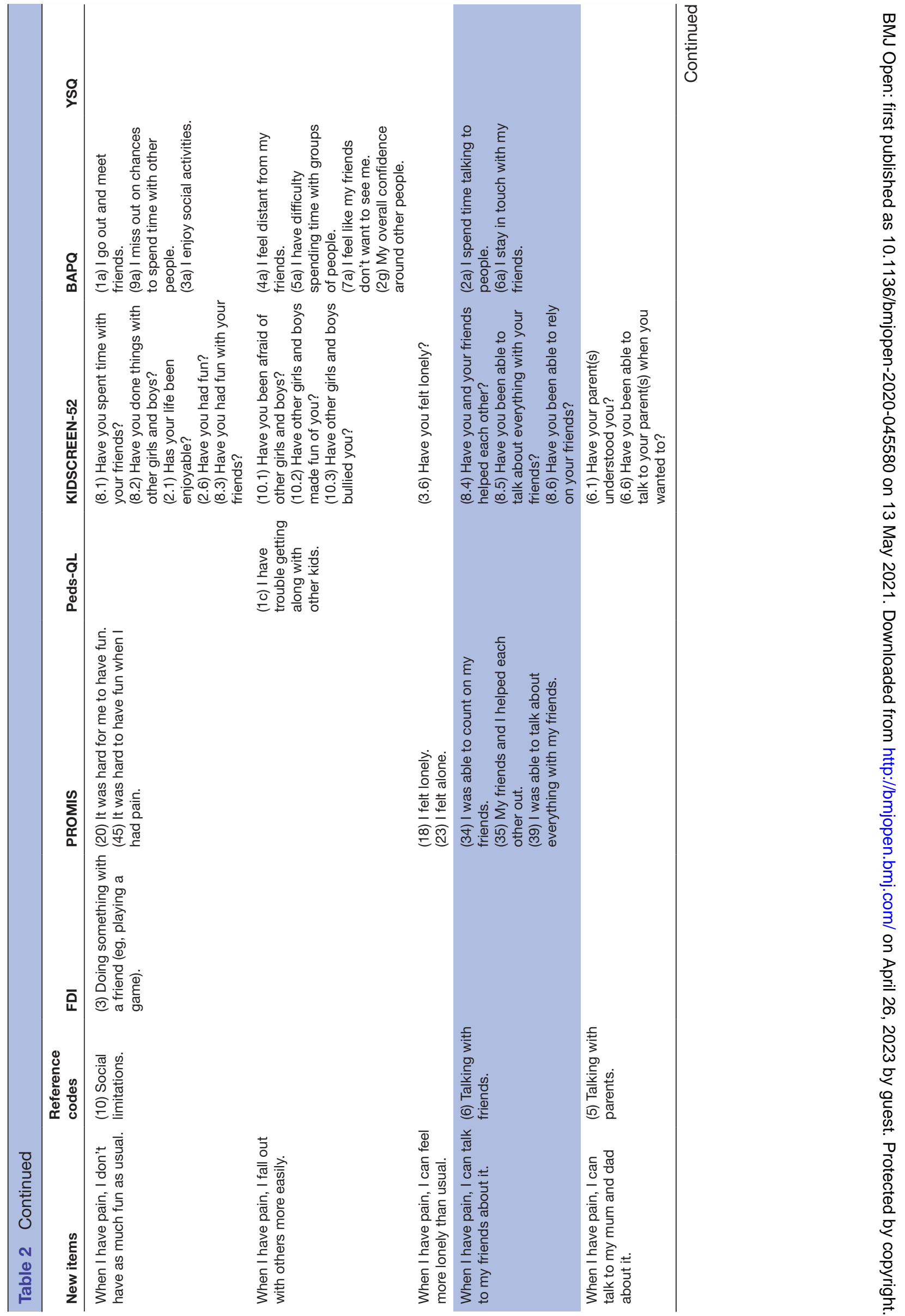




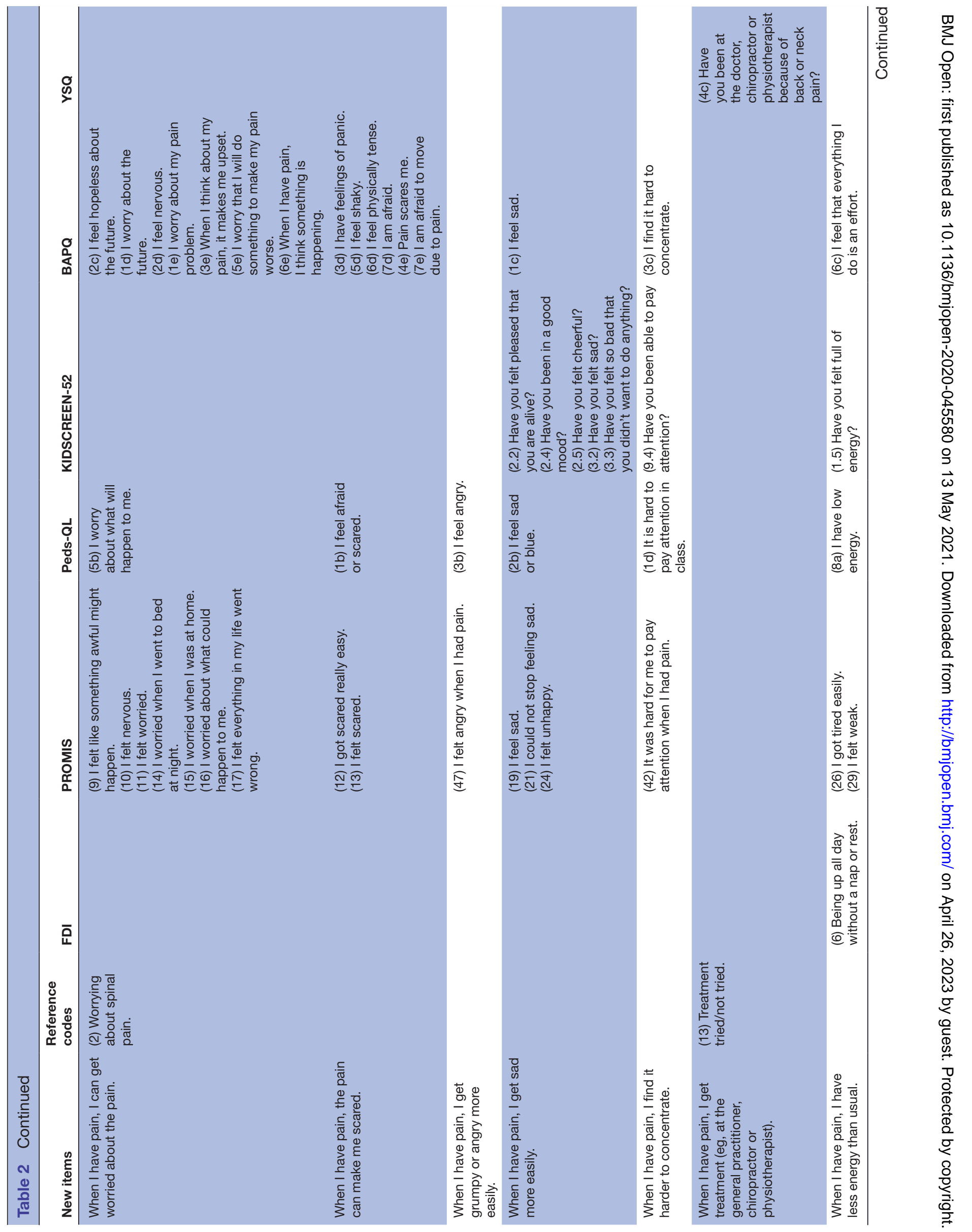




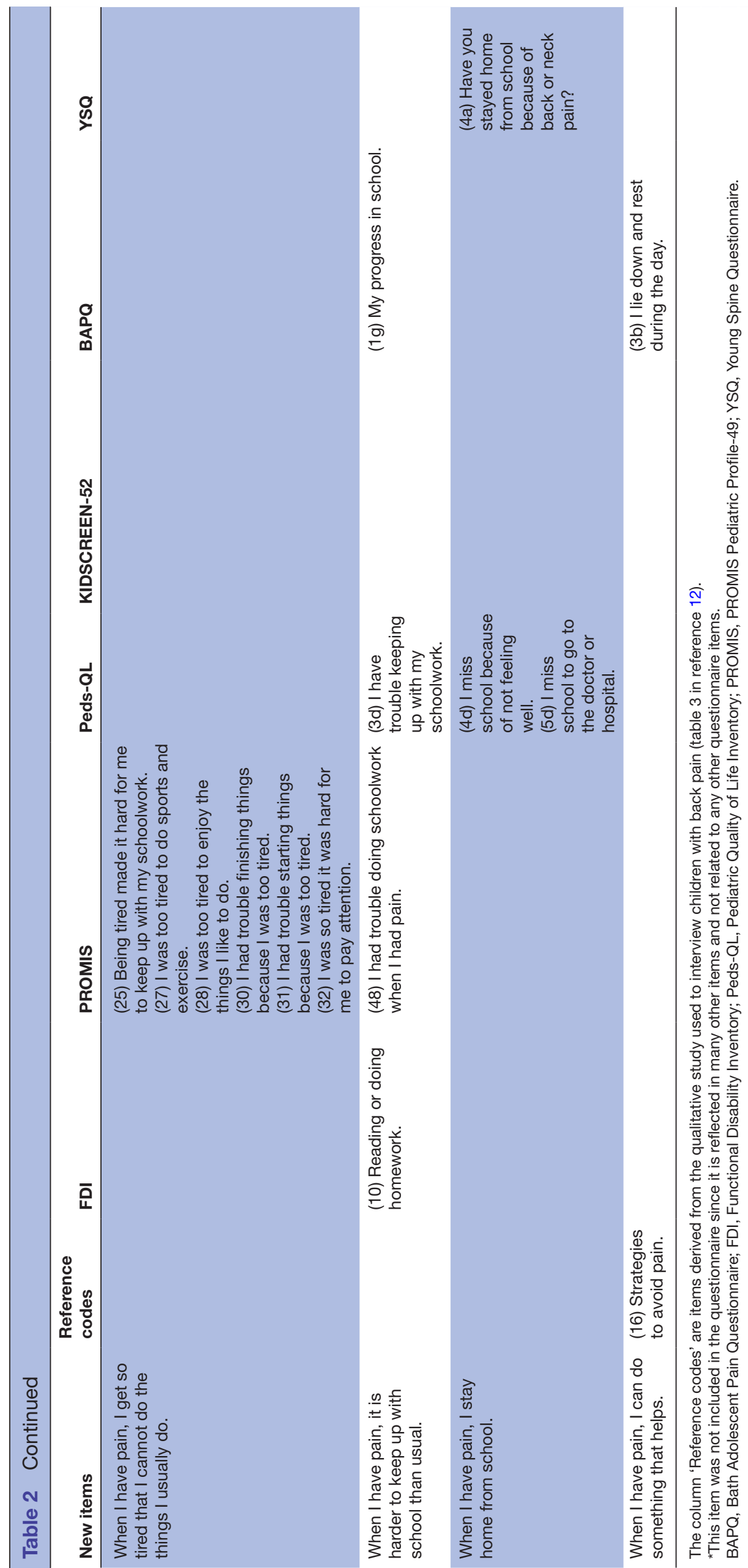

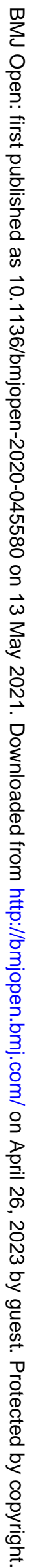


Table 3 Changes made after pilot test 1

\begin{tabular}{|c|c|}
\hline Subject to change & Change made \\
\hline $\begin{array}{l}\text { Response options: never - once in } \\
\text { a while - often - very often - almost } \\
\text { all the time. }\end{array}$ & $\begin{array}{l}\text { Changed to: never - once or twice - } \\
\text { once in a while - often - almost all the } \\
\text { time. }\end{array}$ \\
\hline $\begin{array}{l}\text { 'When I have pain, it is difficult to } \\
\text { stand or sit for as long as I usually } \\
\text { do'. }\end{array}$ & $\begin{array}{l}\text { Split into two: 'When I have pain, it is } \\
\text { difficult to stand for as long as I usually } \\
\text { do', 'When I have pain, it is difficult to } \\
\text { sit for as long as I usually do'. }\end{array}$ \\
\hline
\end{tabular}

\section{Reason for change}

Changed due to difficulty to choose between 'once in a while' and 'often'.

This question was split up to differentiate between standing and sitting. According to the statements from the children, there was a difference between standing and sitting depending on site of pain.

Addition of question: 'When I have pain, This question was added due to comments it is difficult to sit with the neck bend (eg, looking at a phone or homework)'.

'When I have pain, it is difficult to lift Changed to: 'When I have pain, it is as much as I usually can'. question of sitting down. from the pupils. They added this aspect to the

The question was changed to specify the 'heavy lifting'. Not all children lift heavy objects daily, and therefore the question has to be more specific.

Addition of question: 'When I have pain, Several pupils claimed that it hurt when bending it is difficult to bend down'. down for something.

Addition of question: 'When I have pain, Several pupils said that they had pain when it is difficult to ride my bicycle'.

biking to school when asked if there was anything that made the pain worse.

Addition of question: 'When I have pain, Some pupils claimed to be quite and withdraw I become quiet'. from conversations as well as from other social activities when in pain.

'When I have pain, I get more easily sad than I usually do'.

Changed to: 'When I have pain, I get more easily sad or upset'.

Many of the children mentioned 'getting upset' when talking about being 'sad'. Therefore the addition of 'upset'.

$\begin{array}{ll}\begin{array}{l}\text { 'When I have pain, it is harder to } \\ \text { keep up with school than it usually } \\ \text { is'. }\end{array} & \begin{array}{l}\text { Not relevant. Overlapping with question } 16 \\ \text { about concentration. }\end{array} \\ \begin{array}{ll}\text { Last section: 'The worst thing about Changed to: 'What matters most to } \\ \text { having pain in the neck, midback or you, when you have pain in the neck, } \\ \text { low back is...' }\end{array} & \begin{array}{l}\text { It was not all pupils that understood the } \\ \text { formulation of the question. Some thought that } \\ \text { midback or low back?' }\end{array} \\ \begin{array}{l}\text { it was about pain intensity. Therefore it was } \\ \text { changed to 'What matters most to you?' }\end{array}\end{array}$

regarding physical activity such as walking, running and taking care of oneself were included in the activity component, and the three items concerning social activities were included in the participation component. We included psychological well-being and coping strategies in the personal factors component, which included 12 items. The component of body functions and structure included three items regarding sleep, energy and fatigue. The component of environmental factors included one item regarding the use of treatment when having pain.

\section{Field test version of the YDQ-S}

The structure of the field test version of the YDQ-S included a first section derived from the YSQ regarding pain frequency and intensity, ${ }^{15}$ followed by the 28 newly developed consequence items and an additional section that includes the 4 items to show the relative contribution of the four domains. The original Danish version and a translated English version of the questionnaire are shown in online supplemental material 3.

\section{DISCUSSION}

\section{Principal findings}

Several questionnaires used to measure the consequences of pain in children were identified, but none of them was developed specifically for children with spinal pain, and it is clear from table 2 that none of them covers all aspects mentioned by the children. For example, FDI $^{21}$ focuses on the practical consequences of pain and pay little attention to the psychological factors, whereas PROMIS- $49^{22}$ covers the psychological factors well but does not include harder outcomes such as absence from school, which has been described as a major issue,${ }^{56}$ with up to $23 \%$ of children with low back pain reported to have missed school. ${ }^{29}$ Therefore, the need for a new comprehensive questionnaire was confirmed.

The combination of the previously conducted qualitative study ${ }^{12}$ and the literature review supplemented by advice from external experts resulted in an item pool of 35 items, which were reduced to 28 items through the process of item formulation and pilot testing. These 
Health condition

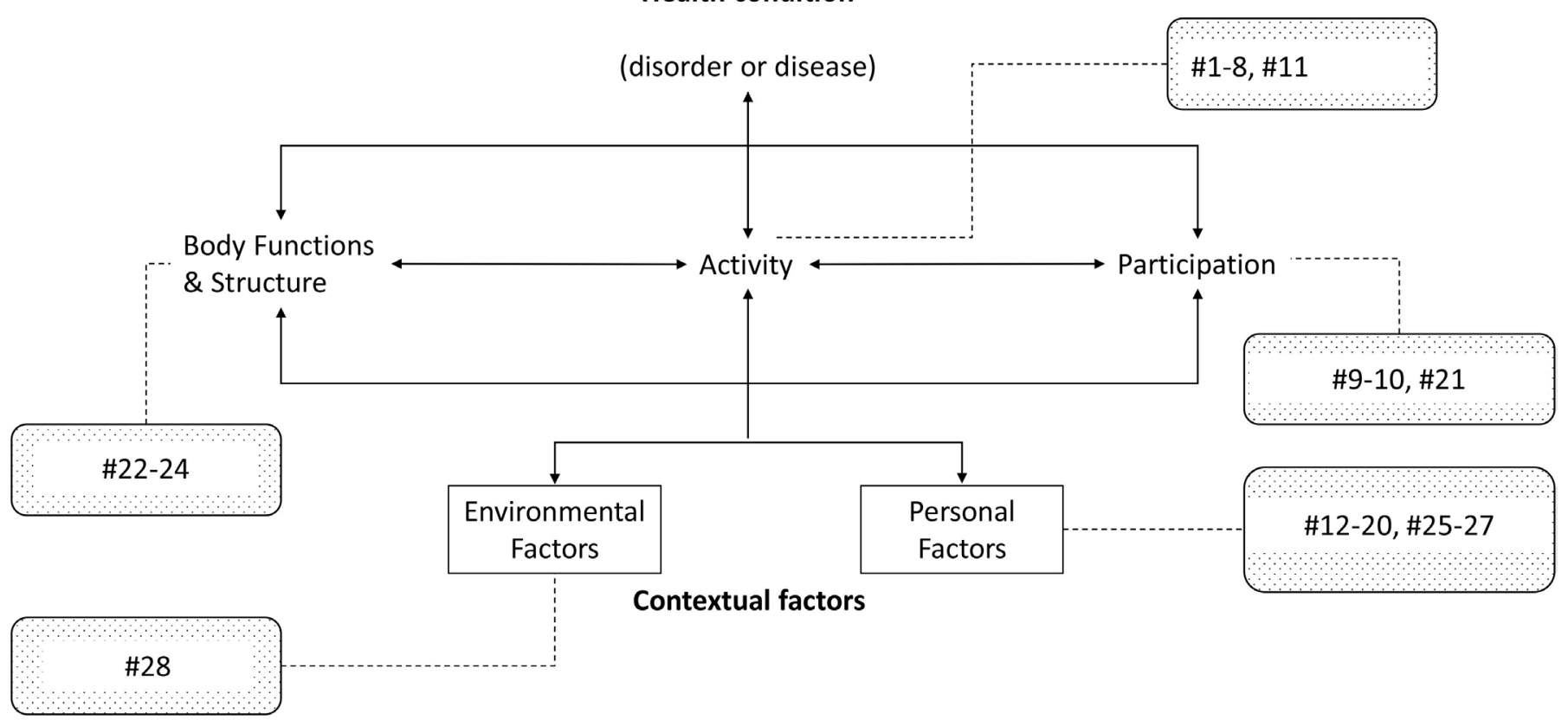

Figure 2 Categorisation of the newly developed items using the International Classification of Functioning, Disability and Health model.

\# refers to the itemnumber in the new questionnaire

items covered all the components included in the ICF model, but with an overweight on the physical activity and personal factors component. The strong representation of the physical activity component reflects both the direct (from pain and/or stiffness) and the indirect (from anticipation of further consequences) effect on movement. The personal factor component was even stronger represented, reflecting a large degree of worry in the children, which was also obvious in the children during the interviews. This was also found by Kashani $e t a l,{ }^{30}$ who emphasised that children are quite worried about their situation when having spinal pain.

The additional section giving relative weight to different domains, which were important for the children in the previous qualitative study, ${ }^{12}$ was also considered relevant and comprehensible for the children in the pilot tests.

\section{Strengths and limitations}

Combining qualitative interview findings with a systematic search of the literature proved to be beneficial to cover all potential aspects of consequences, as neither method was comprehensive by itself. The pilot testing of the resulting questionnaire also turned out to be necessary. Despite much attention paid to careful wording of the items, several formulation changes were required after the pilot tests. We believe the stepwise process has helped to produce a questionnaire which is both comprehensive, covering all relevant aspects of spinal pain consequences, and comprehensible to the age group. However, despite a rigorous literature search, assisted by a research librarian, we cannot exclude that we have missed existing questionnaires which could have added to the item pool. Furthermore, assessment of face validity for inclusion of questionnaires was a rather subjective process and could therefore be a potential bias in the selection of questionnaires to be represented in the item pool. To minimise this bias, all three authors, with different competencies and levels of experience, were involved in the process of assessing the questionnaires for inclusion.

Due to the comprehensive process of identifying relevant items, we believe the item bank to be globally representative. However, the wording of the questions is targeted to Danish children, and the English version of the questionnaire supplied with this manuscript is only included for information purposes and is not yet validated. The population was recruited from a primary school, and completion of questionnaires as well as conduct of interviews were completed during school hours, limiting sampling bias. However, the applicability of the questionnaire in other contexts is unknown.

\section{Next step}

Before the questionnaire can be submitted for use in research and clinical settings, it should first undergo a field test, which is planned in Denmark as well. The structure of the ICF classification makes it possible to organise and summarise data for analysis, even when used on a basic level (eg, without using the code system).$^{19}$ For the subsequent validation of the questionnaire, the ICF model will be used to analyse data with regard to interrelations between the items and to confirm or reject the proposed components. ${ }^{13}$

During the study, we became aware of cultural differences in the formulation of the items-for example, item 4 'It is hard for me to walk more than one block' from Peds-QL, where walking distance is calculated in 'blocks', 
which is a term not used in Denmark. To ensure that the items are applicable, the questionnaire should be submitted to rigorous translation and cross-cultural validation ${ }^{31}$ before being used outside Scandinavia.

\section{Perspectives}

Introduction of a standardised questionnaire to measure the consequences of spinal pain in children can facilitate pooling of research data and thereby optimise the use of research resources in the future. Such evidence is of paramount importance to develop strategies for treatment and early prevention of spinal pain, which will be the largest contributor to the cumulative burden of disease as children grow up, if present disease patterns continue. ${ }^{4}$

A validated and reliable questionnaire can also hold promise for clinicians. A clear understanding of how spinal pain affects children will be valuable to design individually tailored treatment strategies. Not least the additional section, where the child indicates the relative importance of the domains, can help clinicians to focus on the most important aspects to reduce the consequences of pain and thereby improve the long-term health trajectory.

\section{CONCLUSION}

Based on a comprehensive and robust pool of items, we developed the first version of a questionnaire to measure the consequences of back or neck pain in children, representing all components of the ICF conceptualisation model. The process showed the importance of combining research methods, each adding important contributions to the final product.

Since paediatric spinal pain is an important determinant of the children's future health and quality of life, it is of paramount importance to optimise research efforts. Following successful validation, the instrument can be used to enhance the quality of research efforts in the field of paediatric spinal pain. Furthermore, if the questionnaire gains broad acceptance, it can facilitate standardisation to allow future pooling of research results. Finally, it can help clinicians to target the most important issues for each individual child.

\section{Twitter Henrik Hein Lauridsen @hhlauridsen}

Acknowledgements The authors would like to thank the headmaster and school teachers from the participating school for making data collection possible and the pupils for participating in the interviews.

Contributors HHL and LH conceived the study. All authors participated in the design and coordination. EM conducted the literature search. EM and LH drafted the first questionnaire. All authors participated in the interviews. EM drafted the first manuscript. All authors read and approved the final manuscript.

Funding The work was supported by the Faculty of Health of the University of Southern Denmark. The faculty had no influence on the design, strategies or conduct of this investigation.

Competing interests None declared.

Patient consent for publication Not required.

Ethics approval The study was approved by the Danish Data Protection Agency (Nr. 10.075), and the Scientific Ethics Committee of Southern Denmark concluded that the project was not subject to notification due to its design as a method development study (J.Nr. 20182000-114).

Provenance and peer review Not commissioned; externally peer reviewed.

Data availability statement No data are available. Data are not available due to legal (GDPR) and ethical restrictions.

Supplemental material This content has been supplied by the author(s). It has not been vetted by BMJ Publishing Group Limited (BMJ) and may not have been peer-reviewed. Any opinions or recommendations discussed are solely those of the author(s) and are not endorsed by BMJ. BMJ disclaims all liability and responsibility arising from any reliance placed on the content. Where the content includes any translated material, BMJ does not warrant the accuracy and reliability of the translations (including but not limited to local regulations, clinical guidelines, terminology, drug names and drug dosages), and is not responsible for any error and/or omissions arising from translation and adaptation or otherwise.

Open access This is an open access article distributed in accordance with the Creative Commons Attribution Non Commercial (CC BY-NC 4.0) license, which permits others to distribute, remix, adapt, build upon this work non-commercially, and license their derivative works on different terms, provided the original work is properly cited, appropriate credit is given, any changes made indicated, and the use is non-commercial. See: http://creativecommons.org/licenses/by-nc/4.0/.

\section{ORCID iDs}

Henrik Hein Lauridsen http://orcid.org/0000-0001-5198-5215

Lise Hestbaek http://orcid.org/0000-0002-1620-4556

\section{REFERENCES}

1 Dissing KB, Hestbæk L, Hartvigsen J, et al. Spinal pain in Danish school children - how often and how long? The CHAMPS Study-DK. BMC Musculoskelet Disord 2017;18:67.

2 Aartun E, Hartvigsen J, Wedderkopp N, et al. Spinal pain in adolescents: prevalence, incidence, and course: a school-based two-year prospective cohort study in 1,300 Danes aged 11-13. BMC Musculoskelet Disord 2014;15:187.

3 Hestbaek L, Leboeuf-Yde C, Kyvik KO, et al. The course of low back pain from adolescence to adulthood: eight-year follow-up of 9600 twins. Spine 2006;31:468-72.

4 Flachs EM, Eriksen L, Koch MB. Sygdomsbyrden I Danmark sygdomme.

5 Kamper SJ, Henschke N, Hestbaek L, et al. Musculoskeletal pain in children and adolescents. Braz J Phys Ther 2016;20:275-84.

6 Palermo TM. Impact of recurrent and chronic pain on child and family daily functioning: a critical review of the literature. J Dev Behav Pediatr 2000;21:58-69.

7 Van Dijk M, Groen W, Moors S, et al. The Dutch translation of the revised childhood health assessment questionnaire: a preliminary study of score distribution. Clin Exp Rheumatol 2010;28:275-80.

8 d'Hemecourt PA, Zurakowski D, d'Hemecourt CA, et al. Validation of a new instrument for evaluating low back pain in the young athlete. Clin J Sport Med 2012;22:244-8.

9 Clifford SN, Fritz JM. Children and adolescents with low back pain: a descriptive study of physical examination and outcome measurement. J Orthop Sports Phys Ther 2003;33:513-22.

10 Stinson J, Connelly M, Kamper SJ, et al. Models of care for addressing chronic musculoskeletal pain and health in children and adolescents. Best Pract Res Clin Rheumatol 2016;30:468-82.

11 Warming HF. Børneperspektiver : børn som ligeværdige medspillere i socialt og pædagogisk arbejde. Copenhagen: Akademisk Forlag, 2011.

12 Lauridsen $\mathrm{HH}$, Stolpe AB, Myburgh C. What are important consequences in children with non-specific spinal pain? A qualitative study of Danish 9-12-year olds. BMJ.

13 De Vet HC, Terwee CB, Mokkink LB. Measurement in medicine. A practical guide. Cambridge: Cambridge University Press, 2011.

14 Riley AW. Evidence that school-age children can self-report on their health. Ambul Pediatr 2004:4:371-6.

15 Lauridsen HH, Hestbaek L. Development of the young spine questionnaire. BMC Musculoskelet Disord 2013;14:185.

16 Stucki G, Boonen A, Tugwell P, et al. The world health organisation International classification of functioning, disability and health: a conceptual model and interface for the OMERACT process. J Rheumatol 2007;34:600-6.

17 Cieza A, Brockow T, Ewert T, et al. Linking health-status measurements to the International classification of functioning, disability and health. J Rehabil Med 2002;34:205-10. 
18 Gamst-Klaussen T, Gudex C, Olsen JA. Exploring the causal and effect nature of EQ-5D dimensions: an application of confirmatory tetrad analysis and confirmatory factor analysis. Health Qual Life Outcomes 2018;16:153.

19 Ustün TB, Chatterji S, Bickenbach J, et al. The International classification of functioning, disability and health: a new tool for understanding disability and health. Disabil Rehabil 2003;25:565-71.

20 Bakas T, McLennon SM, Carpenter JS, et al. Systematic review of health-related quality of life models. Health Qual Life Outcomes 2012;10:134.

21 Walker LS, Greene JW. The functional disability inventory: measuring a neglected dimension of child health status. J Pediatr Psychol 1991;16:39-58.

22 Irwin DE, Varni JW, Yeatts K, et al. Cognitive interviewing methodology in the development of a pediatric item bank: a patient reported outcomes measurement information system (PROMIS) study. Health Qual Life Outcomes 2009;7:3.

23 Varni JW, Seid M, Rode CA. The PedsQL: measurement model for the pediatric quality of life inventory. Med Care 1999;37:126-39.

24 Ravens-Sieberer U, Gosch A, Rajmil L, et al. KIDSCREEN-52 quality-of-life measure for children and adolescents. Expert Rev Pharmacoecon Outcomes Res 2005;5:353-64.
25 Palermo TM, Witherspoon D, Valenzuela D, et al. Development and validation of the child activity limitations interview: a measure of pain-related functional impairment in school-age children and adolescents. Pain 2004;109:461-70.

26 Wendel-Vos GCW, Schuit AJ, Saris WHM, et al. Reproducibility and relative validity of the short questionnaire to assess health-enhancing physical activity. J Clin Epidemiol 2003;56:1163-9.

27 Magnussen LH, Lygren H, Anderson B, et al. Validation of the Norwegian version ofHannover functional ability questionnaire. Spine 2010;35:E646-53.

28 Eccleston C, Jordan A, McCracken LM, et al. The Bath adolescent pain questionnaire (BAPQ): development and preliminary psychometric evaluation of an instrument to assess the impact of chronic pain on adolescents. Pain 2005;118:263-70.

29 Bejia I, Abid N, Ben Salem K, et al. Low back pain in a cohort of 622 Tunisian schoolchildren and adolescents: an epidemiological study. Eur Spine J 2005;14:331-6.

30 Kashani JH, Orvaschel H, Burk JP, et al. Informant variance: the issue of parent-child disagreement. J Am Acad Child Psychiatry 1985;24:437-41.

31 Acquadro C, Conway K, Hareendran A, et al. Literature review of methods to translate health-related quality of life questionnaires for use in multinational clinical trials. Value Health 2008;11:509-21. 